ESPECIAL

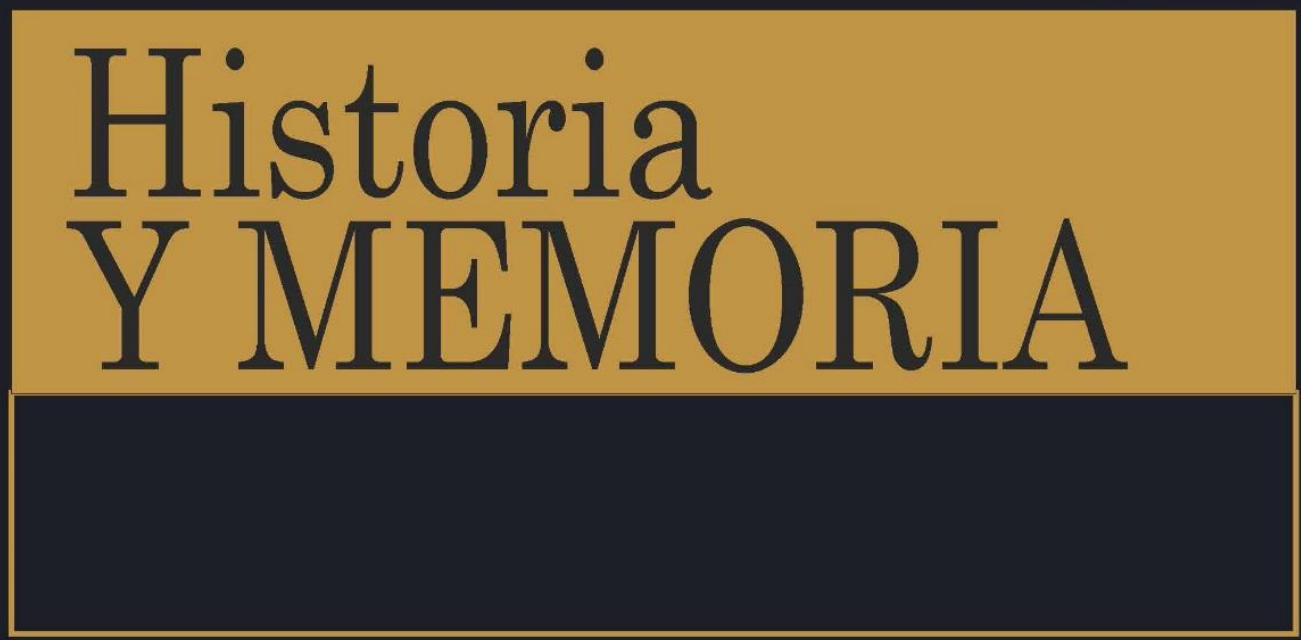

ISSN: 2027-5137 Número Especial • 10 Años • Año 2020 - Tunja, Colombia

\title{
Carlo Ginzburg. Cuando el historiador amoneda un símbolo
}

https://doi.org/10.19053/20275137.nespecial.2020.11591

$$
\text { Justo Serna }
$$

Anaclet Pons

Páginas 307-345

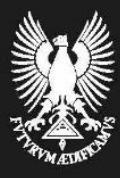




\title{
Carlo Ginzburg. Cuando el historiador amoneda un símbolo
}

\author{
Justo Serna ${ }^{1}$ \\ Anaclet Pons ${ }^{2}$ \\ Universidad de Valencia, España
}

Recepción: 14/01/2020

Evaluación: 22/02/2020

Aprobación: 21/04/2020

Artículo de Investigación e Innovación

https:/doi.org/10.19053/20275137.nespecial.2020.11591

\section{Resumen}

En este artículo pretendemos analizar la trayectoria, la contribución, los resultados y la influencia de un historiador de renombre mundial, Carlo Ginzburg. La suya es una investigación de largo recorrido, cuya influencia se ha dado no solo en esta rama del saber, sino también en muy distintos ámbitos de las humanidades, de las ciencias, de las artes. Carlo Ginzburg ha sido reconocido e identificado principalmente a partir de dos logros historiográficos: la microhistoria y El queso y los gusanos. Por un lado, se le ve como el máximo representante de la microhistoria,

1 Doctor en historia, profesor de la Universidad de Valencia. Pertenece al grupo de investigación «Entre dos mundos. Historia parlamentaria y culturas políticas en los años del Trienio Liberal» HAR2016-78769-P. Últimas 3 publicaciones: Justo serna y Anaclet Pons, microhistoria. Las narraciones de Carlo Ginzburg (Granada: Comares, 2019); Historia y ficción. Conversaciones con Javier Cercas (Madrid: Punto de vista Editores, 2019); Leer el mundo. Visión de Huberto Eco (Madrid: La Huerta Grande, 2017). $\bowtie$ jserna@uv.es (ㄱ https://orcid.org/0000-0002-5003-8109.

2 Doctor en historia, profesor en Historia Contemporánea en la Universitat de València. Perteneciente al grupo de investigación Historia, Memoria y sociedad Digital, Nuevas formas de transmisión del pasado: RTI2018-093599-B-I00 MCIU/AE/ FEDER, UE. Últimas 3 publicaciones: Justo serna y Anaclet Pons, microhistoria. Las narraciones de Carlo Ginzburg (Granada: Comares, 2019); «De la historia local a la historia pública: algún defecto y ciertas virtudes,» Historia Nova: Revista de historia contemporánea, $\mathrm{n}^{\circ}$ extra 1 (2020): 52-80; «El pasado fue analógico, el futuro es digital. Nuevas formas de escritura histórica,» Ayer, nº 110 (2018): 1950.凶 apons@uv.es 주 https://orcid.org/0000-0001-9834-1564. 
la corriente de origen italiano que se expande principalmente en los años ochenta del siglo XX. Por otro lado, a este historiador se le ha identificado con una de sus obras, la de mayor éxito, la de mayor impacto: El queso y los gusanos (1976). La obra de Ginzburg es una reconstrucción individual, con nombre y apellidos, de un sujeto menor, perteneciente al campesinado, a las clases subalternas. Pero la investigación de Ginzburg da un quiebre a partir de finales de los ochenta. Sus nuevos libros tienen un delgado hilo conductor que ata imaginativamente temas muy diversos, pero que puestos en conexión tienen resonancias comunes.

Palabras clave: microhistoria, historiografía, historia cultural, clases subalternas, Carlo Ginzburg, Menocchio.

\section{Carlo Ginzburg. When a historian coins a symbol}

\section{Abstract}

In this article, we intend to analyze the trajectory, contribution, results and the influence of the world-renowned historian, Carlo Ginzburg. His is a protracted investigation, which has not only influenced this area of knowledge, but also very distinct fields of the humanities, the sciences, and the arts. Carlo Ginzburg has been recognized and identified mainly due to two historiographic achievements: microhistory and The Cheese and the Worms. On the one hand, he is seen as the greatest representative of microhistory, a current of Italian origin which expanded mainly in the 1980s. On the other hand, this historian has been identified with one of his most successful works, that with the greatest impact: The Cheese and the Worms (1976). Ginzburg's book is an individual reconstruction, with the name and surnames, of an ordinary individual, who belongs to the peasantry, to a subordinate class. But Ginzburg's investigation comes to a turning point in the late in the 80 s. His new books have a thin connecting thread that links very diverse issues in an imaginative way, which, when put together, show common resonances.

Key Words: microhistory, historiography, cultural history, subordinate classes, Carlo Ginzburg, Menocchio. 


\section{Carlo Ginzburg. Quand l'historien forge un symbole}

\section{Résumé}

Cet article se propose d'analyser le parcours, la contribution, les résultats et l'influence d'un historien de renom mondial : Carlo Ginzburg. Sa recherche est de longue haleine et son influence se perçoit non seulement dans l'histoire mais aussi dans plusieurs domaines des humanités, des sciences, des arts. Carlo Ginzburg a été reconnu et identifié principalement à partir de deux acquis historiographiques: le micro-histoire et Le fromage et les vers. D'un côté, Ginzburg est perçu comme étant le grand représentant de la micro-histoire, ce courant d'origine italienne qui s'est répandu notamment dans les années 80. D'autre part, cet historien reste lié à l'un de ses livres, le plus important : Le fromage et les vers (1976). Ce livre reconstruit l'histoire individuelle d'un homme mineur, un paysan, appartenant aux classes subalternes. Or, la recherche de Ginzburg change à partir des années 80. Ses livres les plus récents partagent un fil rouge qui lie ingénieusement des sujets divers dans lesquels on perçoit, cependant, des résonances communes.

Mots-clés: micro-histoire, historiographie, histoire culturelle, classes subalternes, Carlo Ginzburg, Menocchio.

Quien hace investigación es como una persona que se encuentra en una habitación oscura. Se mueve a tientas, choca con un objeto, realiza conjeturas: ¿de qué cosa se trata?, ¿de la esquina de una mesa, de una silla o de una escultura abstracta? En la investigación de aquello que es desconocido, olvidado e imprevisible, también el azar puede cumplir una función útil. Pero sería ingenuo hacerse ilusiones: no existen atajos para el estudio y estudiar es algo laborioso y cansado ${ }^{3}$.

1. Estudiar cansa, fatiga. Estudiar, nos dice Carlo Ginzburg, es un esfuerzo laborioso que requiere constancia y rigor, algo propio de quien investiga y no abandona al primer tropiezo. $\mathrm{Y}$ hay un sinfín de investigadores, de diferentes disciplinas,

3 Carlo Ginzburg, Prefacio a Tentativas (Morelia: Universidad Michoacana, 2003). 
que obran así, que emprenden pesquisas. Entre ellos, están también los historiadores, que se dedican a indagar sobre el pasado de la humanidad a partir de los restos documentales que quedan. Los historiadores investigan, sí, aunque no todos lo hacen de igual modo, no todos desarrollan y se proponen los mismos temas o se formulan idénticas hipótesis.

Insistamos en ello valiéndonos de la metáfora del cuarto en penumbra: los historiadores se plantean esas mismas conjeturas cuando se mueven a tientas entre el fárrago documental, algo que está en penumbra, sin apenas luz. De hecho, apenas distinguen la luz... Y así, conforme avancen, tropezarán, chocarán con objetos que les resultan desconocidos u olvidados. Es una marcha a veces fácil de completar y a veces llena de dificultades, sin apenas vislumbres, escasos de luces; es una marcha que cada investigador resuelve con mayor o menor fortuna valiéndose de la pericia profesional, pero también de su particular intuición o genio, en el caso de poseer estas cualidades.

Así hay historiadores normales, que se atienen a lo previsible, a lo que de ellos se espera, auténticos profesionales, artesanos del oficio: investigadores que realizan indagaciones más o menos equivalentes a las que cualquier otro colega podría formalizar ajustándose a las reglas profesionales. Nos referimos entre otras a la erudición documental, al análisis empírico y a la comunicación correcta de los resultados.

Pero los hay también que sobresalen por la libertad a la que se atreven o se conceden. Destacan por su audacia: por los temas escogidos, por la forma de su escritura y por la originalidad de sus procedimientos. Son historiadores que, sin saltarse las reglas o la deontología, hacen avanzar el conocimiento a golpe de intuición y de genio. Se convierten así en referencia y hasta en modelo a seguir por sus pares intelectuales e incluso por públicos más vastos, ajenos a los rigores de la profesión.

De los casos que podríamos citar, uno sin duda es el de Carlo Ginzburg. Este historiador italiano, además del método, 
intuición y genio, posee otra cualidad que le hace sobresalir: el hecho simple pero decisivo de haber amonedado un símbolo, el de la microhistoria e incluso el hecho de haber dado todo el protagonismo a un sujeto olvidado de la historia, operación que le obligó a exhumarlo...

Por esa razón, Ginzburg es más un escritor que un escribiente, por decirlo con Roland Barthes ${ }^{4}$. Eso significa que hace suyo e impone, con resistencias y con éxitos, un discurso sensiblemente diferente al previsible. Es por ello por lo que a Ginzburg se vuelve continuamente, para celebrarlo, criticarlo o reexaminarlo.

Los autores influyentes no son solo quienes tienen numerosos seguidores, sino también aquellos que provocan reacciones inevitables, a favor o en contra. Los autores influyentes -entre ellos, ciertos historiadores- son aquellos cuya obra, por ser referente, resulta objeto de constante revaluación y de constante reválida, que son dos operaciones distintas. Es más: un historiador de esta naturaleza es asimismo alguien que regresa una y otra vez sobre su propia prosa, y sobre sus objetos de conocimiento, alguien que se siente obligado a examinar y a reexaminar sus obras como piezas acabadas.

Podríamos decir que la singularidad y la trayectoria de Carlo Ginzburg se desdoblan en dos vertientes relacionadas entre sí. La primera es propiamente el trabajo de archivo, ese lugar físico, sobre el que se desarrolla la práctica de la rutina y el descubrimiento, la evidencia y la sorpresa. En el caso de Ginzburg, los primeros documentos, los más decisivos, fueron las fuentes de la Inquisición, una rutina y un descubrimiento que conforman todo su trabajo posterior y que, como él mismo ha reconocido, resulta incomparable a cualquier otra cosa que le haya sucedido en su dilatada vida como investigador. De esa primera experiencia surgirán tres de sus grandes libros: Los benandanti, El queso y los gusanos y, finalmente, Historia nocturna.

4 Roland Barthes, Ensayos críticos (Buenos Aires: Seix Barral, 2003), 201-211. 
Este último, que lleva por subtítulo Desciframiento del aquelarre, aparece en 1989 y marca el inicio de una segunda fase en su producción, etapa que coincide con el traslado a los Estados Unidos:

Esa experiencia particular de archivo llegó a su fin en 1989, con la publicación de Storia notturna, un libro que buscaba desplegar, en una escala espacial y cronológica completamente diferentes, las implicaciones de mi primero, I benandanti (...). Lo que he hecho desde 1989 es difícil de describir: de entrada, mi trayectoria puede parecer errática ${ }^{5}$.

Puede parecerlo porque se despliega en varias direcciones, con sensores varios y con senderos que se bifurcan y se cruzan. Pero no lo es, como veremos, no es una trayectoria errática, y, en todo caso, remite siempre a lo ocurrido antes de esa fecha, que es la que da sentido y forma a toda su producción.

Carlo Ginzburg nos ha dicho que encontró muy pronto su tema de investigación, así como los referentes textuales que le formaron como académico, que fue muy precoz y que «más tarde, más o menos inconscientemente, traté de distanciarme de aquello en lo que me había convertido, aplicando sobre temas nuevos y desconocidos lo que había aprendido hasta ese momento» ${ }^{6}$. Una voluntad esta, la de separarse, que no ha podido o no ha querido cumplir, porque es en esos años cuando amoneda el símbolo con el que se identifica.

En 2016, Carlo Ginzburg es galardonado en su país con el Premio Sila, concedido por su original carrera académica. A finales de aquel año, y para corresponder a dichos honores, el historiador italiano impartirá una lección magistral titulada «I benandanti, cinquanta anni dopo» ${ }^{7}$. Dice Ginzburg en aquel

5 Carlo Ginzburg, «Interview with 2015 Tanner Lecturer Carlo Ginzburg» (realizada por M. Collins), 6 de marzo de 2015, acceso el 20 de diciembre de 2019, http://mahindrahumanities.fas.harvard.edu/news/interview-2015-tanner-lecturercarlo-ginzburg-matthew-collins.

6 Ginzburg, «Interview with 2015 Tanner Lecturer Carlo Ginzburg».

7 Carlo Ginzburg, «Los benandanti, cincuenta años después,» Taller de letras, ${ }^{\circ} 62$ (2018): 91-101. Traducción levemente retocada. Este mismo texto se ha incluido en la reciente reedición francesa de Les batailles nocturnes (París: Flammarion, 2019). 
texto que los aniversarios le interesan poco y que su regreso al libro de 1966 no depende de un

[...] impulso autobiográfico, sino metodológico: el de intentar entender, aprovechando la contigüidad entre el yo de ahora y el yo del pasado, el porqué de las cosas, por cuáles motivos, conscientes e inconscientes, había realizado las elecciones que me habían llevado a escribir dicho libro ${ }^{8}$.

Al expresarse así, hacía o decía hacer un ejercicio de autoanálisis, una forma de «entender mis reacciones al caso, o sea, al encuentro inesperado con un documento, un nombre, un particular, ojalá marginal $»^{9}$. El encuentro inesperado, la chiripa que, como la fortuna, le llega a quien porfía. ¿Y eso por qué? Porque no hay casos que actúen solos, sino a través de quien «investiga, armado de hipótesis, presupuestos y también -lo quiera o no- de prejuicios. Sin esta disponibilidad de actuar con relación al caso, de lo inesperado, estaríamos condenados a encontrar todo aquello que buscamos: punto y basta. Una perspectiva poco atractiva ${ }^{10}$.

Esa disponibilidad, esa predisposición, va acompañada de conjeturas, hipótesis, presupuestos e incluso prejuicios, una inquietud jamás satisfecha. Insatisfacción que es la que le hace volver sobre sus primeros libros de manera expresa, pero también sobre la microhistoria y sobre la fórmula del indicio, el paradigma indiciario. Lo que de verdad le importa, dice, es «la idea de reflexionar sobre mi propio trabajo después de hecho, con una distancia temporal. Eso está en relación con la edad, con la idea o el propósito de mirar hacia atrás» ${ }^{11}$.

\footnotetext{
8 Ginzburg, «Los benandanti, cincuenta años después,» 91-101.

9 Ginzburg, «Los benandanti, cincuenta años después,» 91-101.

10 Ginzburg, «Los benandanti, cincuenta años después,» 91-101.

11 «Carlo Ginzburg: Secretos de un historiador que busca no aburrir a los lectores, (entrevistado por Gabriela Saidón)", Infobae, Buenos Aires, 16 de octubre de 2018, acceso el 20 de diciembre de 2019, https://www.infobae.com/america/culturaamerica/2018/10/16/carlo-ginzburg-la-historia-y-la-literatura-se-retroalimentan/. Lo mismo indica en "Vivimos en un mundo cada vez más peligroso» (entrevistado por Pablo Marín)», La Tercera, Santiago de Chile, 20 de octubre de 2018, acceso el 20 de diciembre de 2019, https://www.latercera.com/cultura/noticia/carlo-ginzburghistoriador-italiano-vivimos-mundo-vez-mas-peligroso/368062/.
} 


\section{Pero esa inquietud permanente le obliga también a}

[...] reflexionar sobre mi propio caso analizando mi propia historia de la lectura, comparando mi presente con lo que yo era entonces, donde lo que encuentro es solo una coincidencia de nombres. Ahora reflexiono sobre lo que entonces no entendía o no sabía pero que influía en mi manera de escribir, de trabajar, de leer, de actuar ${ }^{12}$.

Eso mismo es lo que nosotros pretendemos, reflexionar sobre Carlo Ginzburg como caso de estudio, centrándonos particularmente en su estilo pronto bien definido y en aquellos símbolos que amonedó en la primera fase de su trayectoria ${ }^{13}$.

\section{En un texto recogido en Otras Inquisiciones, Jorge Luis} Borges se ocupó de Quevedo. En esa pieza aplicaba su lente con su singular clarividencia. Comparaba a Quevedo, su imagen caricaturesca, con la de aquellos otros afortunados que han dado con un símbolo y que así se han apoderado de la imaginación de los lectores:

Homero tiene a Príamo, que besa las homicidas manos de Aquiles; Sófocles tiene un rey que descifra enigmas y a quien los hados harán descifrar el horror de su propio destino; Dante, los nueve círculos infernales y la rosa paradisíaca; Shakespeare, sus orbes de violencia y de música; Swift, su república de caballos virtuosos y yahoos bestiales; Melville, la abominación y el amor de la ballena blanca; Franz Kafka, sus crecientes y sórdidos laberintos. No hay escritor de fama universal que no haya amonedado un símbolo; este, conviene recordar, no siempre es objetivo y externo. Góngora o Mallarmé, verbigracia, perduran como el escritor que laboriosamente forja una obra secreta; Whitman, como protagonista semidivino de Leaves of grass $^{14}$.

El símbolo con el que inadvertidamente dio Ginzburg es múltiple. Es la microhistoria, es Menocchio y es el paradigma

12 "Carlo Ginzburg: Secretos de un historiador que busca no aburrir a los lectores, (entrevistado por Gabriela Saidón)», Lo mismo indica en «Vivimos en un mundo cada vez más peligroso» (entrevistado por Pablo Marín)».

13 Para un análisis en mayor profundidad, véase: Justo Serna y Anaclet Pons, microHistoria. Las narraciones de Carlo Ginzburg (Granada: Comares, 2019).

14 Jorge Luis Borges, Obras Completas II (Barcelona: Círculo de Lectores, 1992), 254 
indiciario. No obstante, en el principio fue $E l$ queso y los gusanos, la obra que dedicara a analizar la cosmogonía de Menocchio, un molinero del siglo XVI, un campesino lector, un vecino que transitaba por su comarca (la de Montereale, en el Fruili) tocando instrumentos musicales, hablando, comentando, tratando de cosas sagradas y profanas. Como consecuencia de esa actividad mundana será encausado por la Inquisición: hasta tal punto eran raras y audaces sus andanzas, sus palabras imaginativas y metafóricas; hasta tal punto eran desviadas o heréticas sus imágenes de un mundo sin Dios, sin origen providencial.

Este caso es, ciertamente, irrepetible y al historiador le servirá para reconstruir con intriga y detalle la persecución y la exclusión, pero también la capacidad creativa, materialista y atea de la cultura popular. Publicado originariamente en 1976, Il formaggio e $i$ vermi provocará grandes efectos en el curso de la historiografía. Quizá lo más atractivo del libro sea su condición de relato erudito y conjetural: ¿por qué Menocchio decía lo que decía?, ¿qué sentido les daba a sus imágenes campesinas del mundo, las del mundo precisamente como un queso?, ¿de dónde procedían sus metáforas?

En un contexto de historia social anónima y colectiva, de historia serial (como la que pregonaban numerosos investigadores de Annales), la vicisitud de un molinero era un episodio menor, una rareza, una excepción o un detalle irrelevante. Pero no era tal cosa. O al menos no solo era tal cosa. Como ha reconocido el autor, su propósito era también y sobre todo mostrar lo pertinente y destacado que era investigar a un individuo intrascendente ${ }^{15}$.

15 Carlo Ginzburg vuelve sobre ello en el posfacio de la reciente reedición italiana, donde indica que no tiene «intención de volver sobre la historia de su recepción, que en gran medida se me escapa; en cambio me gustaría decir algo sobre el contexto en el que nació el libro. Me lleva a hacerlo un tema sobre el que he estado reflexionando durante años: la brecha entre las intenciones de quien escribe (o hace) y los resultados de lo que ha escrito (o hecho)», es decir, entre su intención de llevar la voz de Menocchio al lector y su posterior recepción como ejemplo de la microhistoria. Carlo Ginzburg, $I l$ formaggio e i vermi (Milán: Adelphi, 2019), 211-212. Esas mismas palabras están en el prefacio a la última reedición inglesa: The Cheese and the Worms (Baltimore: John Hopkins University Press, 2013). 
De ese modo, la pesquisa histórica no queda circunscrita al mundo de las élites, sino que se recuperá también para la gente corriente, las masas, el mundo subalterno. Como dirá en 2005, en una entrevista con Trygve Riiser Gundersen:

[...] considero El queso y los gusanos, primordialmente, como un intento de ampliar el campo de pertinencia de la noción del individuo en la historia: de transferir el retrato de la individualidad, del campo de la cultura de elite a lo que generalmente referimos con el término masas $^{16}$.

En todo caso, la magnitud de su éxito, la incidencia de su impacto, así como las razones que él se daba, solo han podido ser medidas con el paso del tiempo. Conversando en 2015 con Iván Jablonka, Carlo Ginzburg intentará ofrecer una respuesta:

\begin{abstract}
Yo mismo me planteé la cuestión: ¿por qué este libro tuvo tal resonancia? En mi opinión, la respuesta está relacionada con el personaje en sí, que es alguien bastante extraordinario. Por otro lado, hay dos temas, dos problemas que están en el núcleo de la relación entre Menocchio y la sociedad en la que vivió, y que también están en el núcleo de mi trabajo. El primero: el desafío a las autoridades, ya sean políticas o religiosas. (...) Segundo tema: las relaciones -digamos, los cruces- entre cultura escrita y cultura oral. (...) Finalmente, está la generalización. A partir de un caso como el de Menocchio traté de plantear cuestiones mucho más amplias. Cuando escribí el libro, en 1976, también había, en la introducción, la preocupación por justificar mi enfoque, una preocupación que ahora puede parecer superflua, pero que tenía ese aspecto de combate. No era nada evidente escribir un libro como este en la década de 1970. Esa introducción teórico-historiográfica es importante, así lo creo ${ }^{17}$.
\end{abstract}

16 Carlo Ginzburg, «På historiens nattside. Carlo Ginzburg i samtale med Trygve Riiser Gundersen,» Samtiden, $n^{\circ} 2$ (2003). (Versión española de Amaranta Süss para sinpermiso: «El lado obscuro de la historia. Entrevista», sin permiso, 12 de marzo de 2006, acceso el 20 de diciembre de 2019, http://www.sinpermiso.info/textos/el-ladoobscuro-de-la-historia-entrevista.

17 Carlo Ginzburg, «La notion de vérité fait partie de nous. Entretien avec Carlo Ginzburg» (realizada por Iván Jablonka), La Vie des idées, 23 de octubre de 2015, acceso el 20 de diciembre de 2019, http://www.laviedesidees.fr/La-notion-de-veritefait-partie-de-nous.html. 
Ese símbolo quedará reforzado unos años después, a finales de los setenta. En efecto, Carlo Ginzburg participó en 1979 en un libro colectivo que tendría una gran repercusión. Su ensayo lleva por título "Spie. Radici di un paradigma indiziario» ${ }^{18} \mathrm{y}$ el volumen en el que se incluye es Crisi de la ragione, editado por Aldo Gargani en los Einaudi Paperbacks, es decir, en la misma colección en que había aparecido $E l$ queso y los gusanos. El ensayo («Spiderman») era una versión ampliada de otro aparecido un año antes.

Tendrá acogida, con diversas reseñas aparecidas en L'Espresso, Alfabeta o Aut Aut e incluso será glosado por Ítalo Calvino en La Repubblica. Es bastante significativo que este literato no haga una recensión de Crisi, sino de "Indicios». Calvino destacará tres cosas. Por un lado, la riqueza de ideas que contiene; por otro, la intención explícita de describir y asumir un paradigma epistemológico contrario a la ciencia galileana $\mathrm{y}$, finalmente, el modelo narrativo que predica a partir de los indicios.

Más adelante, en 1986, Einaudi volverá a publicar el citado artículo en una recopilación de trabajos de Ginzburg bajo el título de Miti Emblemi Spie. Morfologia e Storia. El paradigma del que nos habla Carlo Ginzburg es, pues, un modelo epistemológico que, según dice, habría surgido «silenciosamente» a finales del siglo XIX y que él recupera ahora para la historia a través de tres referentes: Giovanni Morelli, Sherlock Holmes y Sigmund Freud. Así, Ginzburg reúne a autores que, procedentes de las más diversas disciplinas y competencias, pueden tomarse como ejemplos de una genealogía histórica del paradigma indiciario. De ese modo, podemos pensar tales ejemplos como figuras afines que también a él lo describen.

En efecto, como dirá años después, hay en ese ensayo una propuesta teórica y al mismo tiempo, y de una manera

18 Aldo Gargani, ed., Crisi della Ragione (Turín: Einaudi, 1979), 59-106 [Carlo Ginzburg, «Señales. Raíces de un paradigma indiciario,» en Aldo Gargani, comp., Crisis de la razón. Nuevos modelos en la relación entre saber y actividades humanas (México: Siglo XXI,1983), 55-99] 
implícita, hay "una reflexión sobre mi trabajo anterior: una especie de cripto-autobiografía intelectual». Y añadirá:

[...] explotaba entonces las posibilidades de aceleración y de enlentecimiento que me ofrecía la forma literaria del ensayo, para poner juntos, dentro de una narración fragmentada por bruscas discontinuidades, algunos fenómenos separados dentro de un arco que cubría varios milenios: la adivinación de los babilonios, la práctica de los connaisseurs y los principios de la paleografía en la Roma del siglo XVII, el uso de las huellas digitales como instrumento de identificación utilizado por la administración inglesa en la India a finales del siglo XIX, y así por el estilo. Era la hipótesis formulada al principio del ensayo, y que se resumía en la fórmula del "paradigma indiciario", la que permitía mantener el conjunto de toda esta serie de fenómenos tan heterogéneos. Esta hipótesis albergaba las ambiciones teóricas de aquello que se presentaba como un ensayo histórico — si bien se habría tratado de una historia un tanto cuanto particular ${ }^{19}$.

Detengámonos en ello. Nos dice Carlo Ginzburg que ha puesto «juntos, dentro de una narración fragmentada por bruscas discontinuidades, algunos fenómenos separados dentro de un arco que cubría varios milenios». Es algo que recuerda a cierta afirmación de Jorge Luis Borges. En uno de los ensayos incluidos en Otras inquisiciones, el narrador argentino habla de "Kafka y sus precursores». Con ironía desenvuelta, propone también varias referencias de entrada incompatibles (Zenon, Han Yu, Kierkegaard, Robert Browning, León Bloy y Lord Dunsany):

Si no me equivoco -dice Borges-, las heterogéneas piezas que he enumerado se parecen a Kafka; si no me equivoco, no todas se parecen entre sí. Este último hecho es el más significativo. En cada uno de esos textos está la idiosincrasia de Kafka, en grado mayor o menor, pero si Kafka no hubiera escrito, no la percibiríamos; vale decir, no existiría (...). En el vocabulario crítico, la palabra precursor es indispensable, pero habría que tratar de purificarla de toda connotación de polémica o de rivalidad. El hecho es que cada escritor crea a sus precursores. Su labor modifica nuestra concepción del pasado, como ha de modificar el futuro. En esta correlación

19 Carlo Ginzburg, «Reflexiones sobre una hipótesis: el paradigma indiciario, veinticinco años después,» Contrahistorias, $n^{\circ} 7$ (2006-2007): 7-8. 
-concluye- nada importa la identidad o la pluralidad de los hombres ${ }^{20}$.

Esa será, pues, la virtud, pero también el riesgo, del procedimiento de Ginzburg, un riesgo consciente desde el primer momento. En parte, por su atrevimiento disciplinario, porque su propuesta se plantea «de una manera que ignoraba decididamente, no solo las divisiones entre las disciplinas, sino también las jerarquías etnocéntricas habituales» ${ }^{21}$. Y en parte por traducir algo que está en el ambiente: «había sido capaz de atrapar alguna cosa que estaba flotando en el aire, en la atmósfera de esa época, y que le había dado voz a ciertos temas difusos y que se encontraban entonces en estado de reposo, bajo una forma latente» ${ }^{22}$.

Pero, además, ese símbolo, ese slogan, ha perdurado no solo en su propio trabajo, sino en el de muchos otros. Lo demuestra, por ejemplo, un volumen coordinado por Denis Thouard en el que diversos estudiosos se interrogan sobre la pertinencia epistemológica del paradigma indiciario, en particular sobre su capacidad para alimentar un modelo de razonamiento válido para las ciencias humanas ${ }^{23}$.

Pero si hay algo que define a Ginzburg, la parte mollar del símbolo, es el término microhistoria. Es cierto que no hay una coincidencia cronológica entre su obra y la etiqueta con la que se lo reconoce hoy en día: «mi libro El queso y los gusanos (1976), que a veces se ha considerado típico de la microhistoria, fue escrito antes de su teorización. La teoría vino después del hecho, como suele ser habitual $»^{24}$. En efecto, ni en $E l$ queso ni

20 Borges, Obras Completas II, 254.

21 Ginzburg, «Reflexiones sobre una hipótesis,» 8

22 Ginzburg, "Reflexiones sobre una hipótesis,» 8.

23 Denis Thouard, ed., L'interprétation des indices -Enquête sur le paradigme indiciaire avec Carlo Ginzburg (Lille: Presses Universitaires du Septentrion, 2007), DOI: https://doi.org/10.4000/books.septentrion.65335. Otro ejemplo sería la identificación de Ginzburg con (casi su reducción a) ese método detectivesco. Véase Kelly Boyd, ed., Encyclopedia of Historians and Historical Writing (Londres: Fitzroy Dearborn, 1999), vol 1, 468-469. Por otro lado, véase: Luciano Canfora y otros, «Paradigma indiziario e conoscenza storica. Dibattito su 'Spie' di Carlo Ginzburg,» Quaderni di Storia, $\mathrm{n}^{\circ} 11$ (1980): 3-18; $\mathrm{n}^{\circ} 12$ (1980): 3-54; y nº 14 (1981): 159-187.

24 Ginzburg, «La notion de vérité fait partie». 
en Mitos, emblemas, indicios, en donde la palabra clave no es microhistoria, sino morfología.

En un debate organizado en marzo de 1980 a propósito de "Indicios» en Milán, Carlo Ginzburg alude en la última de sus intervenciones al término microhistoria, y lo hace de manera breve y clara, aunque en un doble sentido. Por una parte, se reafirma en que su ensayo propone estudiar objetos y plantear problemas no habituales en la historiografía, para lo cual es necesario introducir nuevos métodos y, como añadía literalmente, renegociar las reglas de control. Por otro lado, confiesa su sorpresa por el hecho de que se asocie necesariamente el término microhistoria a "Indicios», cuando es evidente, y así lo hace constar, que él no usa ese término en dicho ensayo; sin embargo, como reconoce, todo ese proyecto está vinculado a la reducción de la escala de observación, esa que nos ha de permitir reconstrucciones más densas de la trama histórica ${ }^{25}$.

El rótulo, microstoria, comienza verdaderamente a difundirse en 1981, año en que la editorial Einaudi crea una colección con el título de «Microstorie». Es esta una colección cuyo primer volumen será precisamente un texto de Ginzburg, Pesquisa sobre Piero. Se trata de una nueva investigación en la que la historia del arte (un avatar concreto de Piero della Francesca y la repercusión que esto tendrá en su obra) se aborda desde el modelo conjetural que él mismo ha teorizado en «Indicios» y en la que, como en El queso, la indagación resulta sobre todo la revelación de un enigma. Por tanto, su nombre quedará, ahora sí, irremediablemente vinculado a la microhistoria, tanto por el hecho de ser corresponsable de la colección cuanto por haber sido el autor del primero de los volúmenes que se editan.

¿Qué nos dice Carlo Ginzburg sobre este particular? Es en 1994 cuando, a petición de Hans Medick, decide pronunciarse sobre la relación que habría entre su obra y la microhistoria.

25 Carlo Ginzburg, «Intervención sobre el paradigma indiciario,» en Tentativas (Morelia: Universidad Michoacana, 2003), 157-175. 
Ahora bien, esa reflexión no es más que un ensayo breve, preferentemente autobiográfico y que parece el cierre de esa antigua relación. En ese texto, titulado «Microstoria: dos o tres cosas que sé de ella» -en evidente alusión a la conocida película de Godard-, Ginzburg se empeña en una reconstrucción filológica del término, revelando los autores que, a su juicio, lo habrían empleado antes de su masiva difusión ${ }^{26}$.

En ese recorrido filológico, el autor dedica un buen número de páginas a documentar el empleo que el término habría tenido en diferentes idiomas sin que, a pesar de ello, el lector consiga saber cuál es el significado que ese concepto tiene para él.

En primer lugar, nos habla del proceso constructivo de la investigación. Así, los microhistoriadores se caracterizarían por hacer de su trabajo un constructivismo consciente. Si esto es así, en ese caso el historiador está obligado a exponer sus recursos, a analizarlos conscientemente, mostrando las repercusiones de sus elecciones cognoscitivas: qué objetos deberíamos adoptar, qué categorías emplear, qué tipos de prueba utilizar, qué modelos narrativos y estilísticos elegir para transmitir los resultados al lector. En segundo término, la microhistoria se fundaría en una premisa antiescéptica: predicar el constructivismo no tiene por qué significar la adopción de posiciones relativistas.

No obstante, los rasgos se irán perfilando con el tiempo y con los debates sucesivos, quedando fijados una década después. El proyecto historiográfico que representa la microhistoria se caracterizaría finalmente por: la reflexión sobre lo particular, el nexo entre historia y morfología, el problema de la narración, el movimiento alternativo entre lo micro y lo macro, la polémica

26 Carlo Ginzburg, "Microhistoria: dos o tres cosas que sé de ella,» Manuscrits, $\mathrm{n}^{\circ} 12$ (1994): 13-42. De la actualidad de la microhistoria y la necesidad de dar coherencia a su propuesta da buena cuenta que este texto se haya reeditado en castellano inglés e italiano: en la revista mexicana Ruptura, $\mathrm{n}^{0}$ 10-11 (marzo-junio 2002): 11 27; en Robert M. Burns, ed. Historiography (Critical Concepts in Historical Studies (Londres: Routledge, 2005), vol. 4, 183-206; y en Carlo Ginzburg, Il filo e le tracce. Vero, falso, finto (Milán: Feltrinelli, 2006). 
contra el escepticismo posmoderno y, finalmente, la obsesión por la prueba (y no solo el indicio, añadiríamos) ${ }^{27}$.

Serán, como se puede observar, muchos elementos los que se van añadiendo con el tiempo a una idea, la de la reducción de la escala y la atención sobre lo singular, que en sí misma ha dado enormes frutos. Porque, por ejemplo, como ha señalado Dipesh Chakrabarty, centrarse en cuestiones específicas implica otra manera de renegociar las reglas de la disciplina. Porque estudiar una singularidad es hacerlo sobre algo que se resiste a ser reducido a componente de una categoría general, tensando así un lenguaje que suele hablar de lo general, desafiando su impulso generalizador y anónimo ${ }^{28}$.

Así pues, Ginzburg no reniega del símbolo que ha amonedado. Defiende lo dicho en "Indicios», porque aquel texto ya muestra la importancia de la morfología, algo que continuará exponiendo. Preserva el significado de la microhistoria, pues cree que el proyecto que representa no está acabado ${ }^{29}$. Reconoce, eso sí, que esa suerte de examen detallado, esa mirada intensa, tiene una configuración plural, pues es como una mansión de varias habitaciones en la que sus moradores, procedentes de distintas disciplinas, dialogan constantemente. Por eso rechaza que haya compartimentos estancos y que, por ejemplo, se pueda hablar de un modelo de microhistoria social y otro que sea exclusivamente cultural, pues una implica necesariamente a la otra ${ }^{30}$.

27 Carlo Ginzburg, «Prefacio,» en Tentativas, 55.

28 Dipesh Chakrabarty, «La traducción de los mundos de la vida al trabajo y a la historia,» en Al margen de Europa (Barcelona: Tusquets, 2008), 125.

29 Un ejemplo sería su trabajo sobre Jean-Pierre Pury. Véase: Carlo Ginzburg, «Latituds, esclaus i la Bíblia. Un experiment de microhistoria,» Afers, $\mathrm{n}^{\circ} 57$ (2007): 355-373.

30 Por ejemplo: «Carlo Ginzburg: L'historien et l'avocat du diable. Entretien avec Charles Illouz et Laurent Vidal,» Genèses, ${ }^{\circ} 54$ (2004): 112-129, así como la primera parte contenida en el $n^{0} 53$. (2003): 113-138. En cambio, para Edoardo Grendi, otro de los referentes de la microhistoria italiana, existiría su propia versión «vinculada a la contextualización social (distinta de la conceptualización cultural de Ginzburg)», en la que Grendi propondría "procedimientos analíticos diferentes, referidos a la reconstrucción de las redes de relaciones y a la individualización específica de la 
En cualquier caso, la presencia de El queso y los gusanos, su obra más conocida, la que acaba por amonedar el símbolo de forma retrospectiva, le incomoda. Cuando Trygve Riiser Gundersen le preguntaba qué siente al volver a esa obra, Carlo Ginzburg responde que experimenta cierta fatiga y reitera que su valor tiene esos márgenes concretos a los que ya hemos aludido: su contribución a la historia social será la de ampliar el campo de pertinencia de la noción del individuo ${ }^{31}$.

No obstante, su propuesta peligra si se queda solo en la voluntad de crear una contracultura histórica, empeñada en construir una galería de héroes derrotados. De hacerlo así, se corre el riesgo de convertir la historia en ideología ${ }^{32}$. Por eso, afirma mantener una relación ambivalente con su obra, algo que a muchos de sus lectores ha de sorprender. Conviene en que, si bien es su libro de mayor éxito, no tiene claro que sea el mejor de cuantos ha escrito. Puede que él no lo considere de ese modo, pero el número de lectores le contradice. En el fondo, no obstante, no es tan extraño que algo así suceda.

Como él mismo reconoce, en 1976 y después no estaba preparado para ver cómo tantos y tantos lectores se apropian de su texto de formas diversas y para fines distintos. Todo ello es bastante irónico, añade, pues el volumen, entre otras cosas, trata precisamente de eso, del control que el lector ejerce sobre lo que lee, de cómo un molinero se apropia de los volúmenes que llegan a sus manos en una remota aldea del Friuli.

Sea como fuere, Menocchio ha adquirido desde entonces una celebridad imprevista que sobrepasa el ámbito académico

elección (individual y colectiva)». Edoardo Grendi, «¿Repensar la microhistoria?,» Entrepasados. Revista de Historia, $\mathrm{n}^{\circ} 10$ (1996): 131-140.

31 Ginzburg, «El lado obscuro de la historia. Entrevista,»

32 «para mí, no se ha tratado nunca de construir un panteón de las víctimas. Esta es una tentación contra la que batallo. Me preocupa el riesgo de transformación de la historia en ideología. En mi trabajo, evidentemente existe un vínculo muy fuerte con los muertos. Existen muertos que obsesionan, los muertos con los que estoy vinculado por un sentimiento de identificación emocional. Pero los muertos no son en absoluto las únicas víctimas; también lo son los verdugos, cuya relación con el mundo es igualmente compleja»: Carlo Ginzburg, «De près, de loin. Des rapports de force en histoire. Entretien avec Carlo Ginzburg,» (realizada por Philippe Mangeot) Vacarme, $\mathrm{n}^{\circ} 18$ (2002): 4. 
y que, por ejemplo, ha tenido una de sus últimas muestras en la película estrenada en noviembre de $2018^{33}$. A su vez, tal éxito ha permitido que el apellido del historiador italiano se haya convertido en revelador y exponente de los avances de una nueva forma de hacer historia.

Hace unos años, por ejemplo, Anthony Grafton intentaba repasar los registros historiográficos de finales del siglo XX. Ante la dificultad de recopilar tanta variedad, decidía escoger un ejemplo de los cambios acaecidos: la microhistoria. Y añadía que esta práctica, que a su juicio cuenta con obras maestras como las escritas por Le Roy Ladurie y Ginzburg, se habría convertido en menos de una década en un género establecido, con sus seminarios, sus cursos y un buen número de publicaciones ${ }^{34}$.

Puede, como dice Ginzburg, que Menocchio no haya sido oído como él quisiera y propuso, siguiendo sus instrucciones, pero ha sido leido profusamente, de las formas más insospechadas, identificando a su autor con el nombre del molinero ${ }^{35}$. Y aunque siempre se ha resistido a que se le identifique de ese modo, podría decirse que se ha resignado a ello:

[...]un libro mío, titulado El queso y los gusanos, que ha sido traducido a muchos idiomas, incluido el ruso, ha sido considerado, paradójicamente, como una especie de ejemplo típico de microhistoria. Dije "paradójicamente", porque el libro se publicó en 1976 y las discusiones sobre la microhistoria comenzaron unos años más tarde, en torno a 1978-1979. Retrospectivamente, puedo ver mi propio libro como un ejemplo de investigación que podríamos considerar

33 La película, titutala «Menocchio», ha sido dirigida por Alberto Fasulo y producida por Nefertiti Film.

34 Anthony Grafton, «History's postmodern fates,» Daedalus Vol. 135, nº 2 (2006): $54-69$.

35 Coincidiendo con la reedición de Il formaggio, Carlo Ginzburg dice: «la próxima traducción de $I l$ formaggio e $i$ vermi se lanzará en China. Quién sabe cómo se leerá. Quizás alguien piense en el niño que desafió a los tanques en la Plaza Tiananmen». "La Storia o è eretica o non è Storia entrevista por Simonetta Fiori», La Repubblica, Roma, 11 de septiembre de 2019, acceso el 20 de diciembre de 2019, https://rep. repubblica.it/pwa/intervista/2019/09/11/news/carlo_ginzburg_la_storia_o_e_ eretica_o_non_e_storia_-235698431/. 
que permite una especie de teorización de la microhistoria; al fin y al cabo, es bastante normal que las teorías aparezcan después de los hechos, mejor dicho, después de las exploraciones empíricas ${ }^{36}$.

3. En el primer volumen de Tu rostro mañana, el escritor Javier Marías señala que el problema y las limitaciones de tantos y tantos individuos son la falta de persistencia. En cuanto alguien alcanza una idea brillante o amoneda un símbolo, de inmediato recibe opiniones e interpretaciones y algunos le tienen por lumbrera, genio o gigante. No es difícil que el autor acabe admitiéndolo, al menos como posibilidad, y que tome conciencia de su valía, con lo que desde entonces queda prisionero del hallazgo inicial, temiendo no estar a la altura de sí mismo en sus obras posteriores.

Puede pensar, señala Marías, que lo escrito no tuvo nada que ver con el azar, con su intuición o su libertad, sino que desde siempre hubo coherencia y propósito, de modo que queda condenado a no desmerecerse. Basta, pues, con que se imponga una explicación plausible de nuestro proceder o una elogiosa valoración de nuestro método para que abandonemos el rumbo mudable, imprevisible e incierto de la creación; para que nos repitamos.

No puede decirse algo idéntico de Ginzburg. Él mismo ha reconocido el temor a verse arrollado por la vanidad, incluso a que eso le llevara a convertirse en una figura plenipotenciaria, una suerte de "todólogo", dispuesto a pontificar sobre cualquier $\operatorname{cosa}^{37}$.

En contrapartida, es un investigador que cada vez más se ha dejado llevar por su genio, por su intuición, por objetos

\footnotetext{
36 «Microhistory. Historian Carlo Ginzburg on the value of an individual, geopolitical traditions in history and globalization,» Serious Science, acceso el 20 de diciembre de 2019, http://serious-science.org/microhistory-2893 y https://www. youtube.com/watch?v=VFh1DdXToyE.

37 Así lo señala en el mencionado «Prefacio» del citado volumen recopilatorio Tentativas, 55 .
} 
distintos, por el azar antes que por la curiosidad deliberada y reiterada ${ }^{38}$.

En 2015, con motivo de una Tanner Lecturer impartida en Harvard, será entrevistado por Matthew Collins, quien le pregunta precisamente sobre la coherencia de su obra, en particular sobre la posterior a Historia nocturna, ese momento en que, como decíamos, cierra un determinado trato con los archivos y abre una nueva etapa, repleta de nodos aparentemente dispares, como Dante, Thomas Moro o Blaise Pascal, entre muchos otros. Collins le pregunta si hay en ello alguna intención oculta, a lo que responde:

Lo que he hecho desde 1989 es difícil de describir: de entrada, mi trayectoria puede parecer errática. Sin embargo, veo en ella cierta lógica. De hecho, me mueve siempre el mismo sentimiento: la euforia de la ignorancia, la emoción que experimenta quien ignora temas con los que no estaba familiarizado. En primer lugar, diría, es un placer: me encanta enseñar, pero me encanta mucho más aprender. Pero probablemente hay otra razón más oculta. Encontré mi tema de investigación, junto con los libros que me formaron profundamente como académico, cuando estaba en la veintena. Ser precoz no es necesariamente una dicha. Más tarde, traté, más o menos inconscientemente, de separarme de lo que había llegado a ser, probando lo que había aprendido hasta el momento sobre temas nuevos y desconocidos. La casuística fue uno de ellos. Me lo encontré por primera vez en un ensayo sobre Maquiavelo titulado Maquiavelo, la excepción y la regla: notas de una investigación en curso. Luego vino Pascal, y sus oponentes: los jesuitas. (...) Una vez más, escribir historia y reflexionar sobre el oficio del historiador estuvo indisolublemente conectado, como siempre lo ha estado desde mis primeras experiencias en los archivos friulanos ${ }^{39}$.

38 Según él mismo reconoce, es el azar, y no la curiosidad deliberada, el que explica la elección de temas contenidos en Ninguna isla es una isla (Villahermosa: Universidad Juárez Autónoma de Tabasco, 2003). Véase el segundo párrafo de la «Introducción», 11.

39 Ginzburg, «Interview with 2015 Tanner Lecturer Carlo Ginzburg», Ginzburg se refiere aquí a su texto "Maquiavelo, la excepción y la regla. Líneas de una investigación en curso,» Ingenium, $\mathrm{n}^{\circ} 4$ (2010): 5-28. Véase, asimismo, su reciente Nondimanco Machiavelli, Pascal (Milán: Adelphi, 2018). 
La coherencia y el propósito están, pues, en otro lugar, en esas probaturas, en la manera de disponer la trama de sus narraciones, en el sentido de la intriga. Conforme ha ido desarrollando sus investigaciones y conforme ha ido asentando su influencia intelectual, Carlo Ginzburg se ha ido expresando con mayor libertad, saltándose ciertas barreras académicas.

Como un observador audaz, sabe que el pasado nos llega mediante documentos que son presencia y ausencia. Por un lado, pregonan hechos que ya sucedieron y de los que no hay vestigio abundante o sobrante, hechos cuyo significado se nos resiste: significado oscuro, limitado o parcial. Por otro, esos documentos nos llegan en un soporte cuyas reglas de funcionamiento hay que aclarar, cuya retórica hay que detallar y cuyo género expresivo hay que precisar.

En principio, el mundo siempre es el espacio de lo fragmentario y hermético, como lo es un archivo o una biblioteca inagotables. Es allí, en esos recintos que son metáfora del universo, en donde el historiador experimenta una dicha auténtica, justamente cuando halla documentos confusos, sesgados, o libros ilegibles que, a la postre, consigue descifrar. Un legajo lleva a otro legajo, un libro lleva a otro libro, y esos materiales acaban siempre contagiándose y fertilizándose: gracias a esos testimonios de otro tiempo reconstruimos una parte infinitesimal de un entero cuya totalidad ignoramos.

Por tanto, más que un detalle de lo conocido, los documentos históricos son fragmentos o trozos de un conjunto que conjeturamos. Así obra Carlo Ginzburg y así lo ha admitido en sus últimos libros.

En efecto, tal vez, el mejor ejemplo de lo que decimos se refleje en sus volúmenes, propiamente de ensayo, recopilaciones de sus estudios breves, fragmentarios, que ha ido publicando desde los años noventa. No se trata solo de reunir textos cortos, esas piezas efímeras que se publican en esta o en aquella revista, sino de darles coherencia, de imaginar retrospectivamente qué tienen en común estudios 
diferentes, estudios que arrojan luz sobre una parte siempre escasa.

Imaginar retrospectivamente una coherencia no significa inventar o fantasear: quiere decir, tantear un significado global a partir de la autoría, ensayar un hilo conductor que tenga que ver con ese historiador preocupado básicamente por los mismos temas, por los mismos enigmas históricos, por las mismas ignorancias. Uno puede cambiar de asunto o de cronología, pero el acicate suele repetirse y perdurar: aquello que se desconoce y que con obstinación tratamos de abordar y quizá de aclarar.

Ginzburg parte siempre de una certidumbre presuntamente trivial: la realidad es vasta, plural, multiforme y a ella se puede acceder a través de distintas vías. Insistimos: esa realidad es en sí misma algo cifrado o, al menos, algo cuyo significado no está dado de antemano. En los pliegues de dicha realidad -es decir, en sus manifestaciones materiales e intelectuales- no solo hay algo bien visible, un acto que se materializa o produce, sino también esos ecos e influencias que tal vez fueron perceptibles para aquellos antepasados, pero que ya no lo son para nosotros.

Esto significa que lo real siempre es enigmático en este sentido: en el sentido de que los contemporáneos, leemos o escuchamos superficialmente, limitadamente, con escasez informativa, con tosquedad significativa. El observador es decir, el historiador o aquel analista...- reconoce, pues, la distancia que le separa del pasado, aventurándose en un mundo del que solo quedan vestigios, y lo hace con una mirada sintomática, semiótica, detectivesca: explora los restos, los materiales para trabar entre ellos una relación.

Por supuesto, parte de una pregunta, pero esa inquisición necesita documentos que puedan vincularse entre sí. La correspondencia que el historiador predique es una presunción intrépida y prudente a un tiempo: un observador atento, bien entrenado, bien informado, con múltiples referencias, es una especie de sensor. Insistimos: una cosa lleva a la otra, unas 
palabras recuerdan a otras, una forma reproduce parcial o totalmente otra. El historiador no es un tipo rutinario que aplique normativamente las reglas de la profesión: Ginzburg no obra así.

En realidad, el investigador sería como un científico que acepta la posibilidad de la serendipia, de la casualidad afortunada a partir de la cual es factible averiguar cosas insospechadas, inauditas. Más aún, un historiador agudo sería como un detective entrenado que percibe con una sutileza mayor que la que otros colegas demuestran. No se conforma, no se consiente: un dato material es un fenómeno que convoca todo tipo de hipótesis y que provoca múltiples relaciones posibles.

4. Tomemos como ejemplos, como banco de pruebas, uno de esos libros de Carlo Ginzburg, uno que podría estar entre los más extraños o menos previsibles. Nos referimos a Occhiacci di legno (1998).

Este volumen es el primero de una serie relacionada, vinculada, en la que se incluyen Rapporti de forza (2001), Nessuna isola è un'isola (2002) y Il filo e le tracce (2006) o Nondimanco. Machiavelli, Pascal (2018). El primero de esta serie es una obra que rinde homenaje a Pinocho, de cuyo relato propone un exergo: "Occhiacci di legno, perchè mi

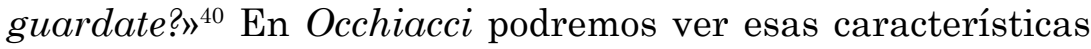
que enunciábamos más arriba y que sintetizan el modo de ver la historia: podremos ver en qué Ginzburg se separa de los historiadores comunes y «metódicos».

Imaginemos la escena. De repente, un ávido lector que deambula entre las novedades de una librería, repara en Occhiacci. Al hurgar entre los anaqueles en donde se yuxtaponen y multiplican los libros, no sería extraño que se interesara por un volumen de título tan ambiguo e inaudito: Ojazos de madera. Nueve reflexiones sobre la distancia.

40 Ginzburg, Ojazos de madera. Nueve reflexiones sobre la distancia. 
Colocado entre las obras catalogadas como de «no ficción», el curioso no acierta a entender el objeto y su razón. Quizá el subtítulo, quizá la contracubierta, quizá el índice, le permitan averiguar que, en efecto, no es un texto común, que es una obra difícil de clasificar, una obra que exige de los libreros imaginación, competencia y experiencia para poder identificarla y etiquetarla.

Para unos, podría formar parte de la sección de historia, pues reconocería en Ginzburg a un autor distinguido de esa disciplina; otros podrían incluirla en la de antropología, dado que su tema, el de la distancia, parece aludir al problema de la comunicación entre culturas y al de la comprensión del otro; y, en fin, habría quien podría tomar Ojazos por un texto de estética, atendiendo a algunos de los conceptos clave que allí se tratan, propios de la crítica literaria o del arte.

Probablemente -concluiría el librero avispado-, la mejor solución sea la de depositarlo en ese apartado inespecífico que denominamos ensayo y que recoge aquellos volúmenes incómodos y variopintos que rebasan los límites de las distintas disciplinas, aquellos volúmenes ambiguos que interpelan a especialistas de diversos géneros ${ }^{41}$.

Mayor razón para esta conclusión, si, además, ese librero hipotético averigua que la traducción al castellano viene precedida por el dato trivial, pero incontestable de haber sido una obra galardonada en Italia con dos célebres premios literarios en el apartado de ensayo ${ }^{42}$.

41 El propio Ginzburg reconoce la forma ensayística de esos volúmenes («de hecho, durante treinta años, publiqué libros que no eran ensayos. Esta elección llegó bastante tarde en mi itinerario»), algo que atribuye a las distintas fuentes ahora utilizadas, diferentes de las empleadas en sus primeros libros, las cuales le imponían ciertas «restricciones». Véase: Carlo Ginzburg, «Entretien: Carlo Ginzburg dialogue avec Éric Dayre,» en Imagination et histoire: enjeux contemporains, dir. Marie Panter y otros (Rennes: Presses Universitaires de Rennes, 2014), 111-124, edición en digital, https://books.openedition.org/pur/49600.

42 Eso mismo ha ocurrido con su último libro -Nondimanco Machiavelli, Pascal (Milán: Adelphi, 2018)-, que ha sido galardonado en 2019 con el «Premio Letterario Internazionale Giuseppe Tomasi di Lampedusa», siendo el primer «ensayo» premiado tras la larga lista de literatos que lo han obtenido desde 2003. 
Como se sabe, este género, el del ensayo, permite un tratamiento más libre de ciertos temas y objetos de conocimiento. Por dos razones. Primera: por ser variados los referentes que se emplean, procedentes de disciplinas diversas. Segunda: por dejar el autor su impronta, una marca de subjetividad explícita, sin cancelar su yo o al menos la expresión transfigurada de su yo. Así lo admitió Theodor W. Adorno y así lo repite expresamente Ginzburg en $\mathrm{Il}$ filo e le tracce.

Así pues, una vez amonedado el símbolo, identificado con él, Carlo Ginzburg desorienta al lector sometiéndolo al vertiginoso hermanamiento de temas diferentes con resonancias comunes. Eso parece llevarles (al autor y a quienes lo leen) por un rumbo mudable, imprevisible e incierto. Giovanni Levi, su colega en el proyecto de la microhistoria, lo decía del siguiente modo, marcando las diferencias entre ambos:

Hay muchas técnicas. Voy a usar como ejemplo a alguien que, para mí, es un gran escritor, antes y además de un buen historiador: Carlo Ginzburg. Tiene la capacidad de decir en la página 200 lo que quería decir. Generalmente, hablamos en la primera línea de lo que queremos decir. 'Este libro demostrará que... etcétera'. Carlo Ginzburg, no. Él guía al lector a lo largo de 200, 250 páginas, por calles misteriosas. No sabes a dónde irás. Al final, muchas veces, dice: 'esa era una calle sin significado'. Pero al final, dice adónde quiere conducirnos. Creo que esta técnica es muy persuasiva. Una de las causas del éxito de Carlo Ginzburg es su capacidad literaria, su capacidad de convencer, porque el lector ya está hipnotizado cuando llega a la página 200, inmerso en un laberinto y ansioso por saber lo que va a suceder al final. Es como una novela policiaca. No es ninguna coincidencia que a menudo Ginzburg establezca relaciones entre historia y novela detectivesca, porque nuestra investigación, muchas veces, es semejante a la investigación policial, buscamos cosas sin saber quién es el asesino ${ }^{43}$.

43 Giovanni Levi, «O trabalho do historiador: pesquisar, resumir, comunicar,» Revista Tempo, $\mathrm{n}^{\circ} 20$ (2014): 3-4. 
Ahora bien, más allá del evidente efecto hipnótico, el lector puede muy bien preguntarse qué asunto aborda realmente Ginzburg en estas obras. $\mathrm{O}$ en otros términos: ¿aparte del tema explícito hay un subtexto? La respuesta, ahora y en sus libros anteriores, es siempre la misma. Hay distintos objetos yuxtapuestos, asociados, subordinados, tratados con suficiente aparato documental y, a la vez, con medida ambigüedad y estudiada imprecisión.

En realidad, si todo gran autor tiene una única obra cuya urdimbre va tejiendo con los hilos de sus diversos trabajos, en el caso de Ginzburg eso también se hace evidente. Esos objetos yuxtapuestos, esos temas y las preocupaciones que le mueven, son recurrentes y varían de acuerdo con el énfasis que pone en cada momento o de acuerdo con los modos de presentación.

Por eso mismo, las obras de Ginzburg ni se modifican ni se corrigen ni se actualizan, dado que son ensayos cerrados en donde el autor ha arrancado una parte de sí mismo volcándola en la escritura. Son retratos (autorretratos) de cada una de las épocas del propio autor que no consienten retoques. No significa eso que cada uno de estos volúmenes sean equivalentes, sino que a través de textos distintos se exponen formas diversas de plantear ideas y preocupaciones recurrentes: la distancia, la retórica, la prueba, la verdad, la ficción, etcétera.

Aunque, eso sí, en cada libro uno de estos aspectos aparece con mayor claridad, sin desentenderse de los otros, pues todos ellos forman parte de la obra de Ginzburg.

Así pues, cuando nos preguntamos sobre la coherencia en esas obras o sobre si ese propósito proviene de antiguo, la respuesta podría ser que Carlo Ginzburg ha desarrollado un programa de investigación sobre la forma, cuyo objeto es el siguiente: modos en que la historia representa la realidad $^{44}$. Con ello incide al menos sobre diversos aspectos que complementan y actualizan su símbolo.

44 Carlo Ginzburg, El hilo y las huellas. Lo verdadero, lo falso, lo ficticio (Buenos Aires: FCE, 2010), 9-18. 
En primer lugar, un determinado tipo de escritura, muy asociada a la práctica ensayística: una escritura tentativa, fragmentaria, en la que puede mostrarse a sí mismo y al objeto, un tipo de narración que Ginzburg reconoce haber utilizado de manera casi exclusiva en los últimos años ${ }^{45}$, aunque la ha tenido siempre en mente ${ }^{46}$. Confiesa que esta forma de exposición escrita proviene de cuando, siendo joven, leyó un ensayo de Luigi Einaudi ${ }^{47}$. Su ensayo, añade, estaba construido como una serie de párrafos numerados, un recurso que relacionó con su propia fascinación por el cine y el montaje.

Esa es otra palabra clave según Ginzburg, montaje: se corresponde con el elemento constructivo que tienen los estudios históricos, dejando claro que nuestro conocimiento es fragmentario y que deriva de un proceso abierto. Dicho de otro modo:

[...]se puede releer la literatura a la luz del cine, pero también se puede escribir la historia como si se tratara de una secuencia resultado del montaje, en el que hay un primer plano, un plano general y así sucesivamente. Desde que empecé a escribir historia he utilizado recursos gráficos para crear efectos de montaje, en particular los párrafos numerados ${ }^{48}$.

Sin embargo, hemos de añadir que Ojazos y otros libros semejantes son volúmenes en los que hay una forma de ensayo peculiar, caracterizado por la heterogeneidad de los asuntos tratados y la sutil coherencia retrospectiva que los hilvana. Ginzburg señala a este respecto que quizá la progresión tortuosa, caprichosa, y discontinua del ensayo parezca poco acorde a las necesidades del trabajo histórico, al rigor de la prueba en particular; sin embargo, objeta que eso permite

45 «Introducción» a Ninguna isla es una, 11-12.

46 Ginzburg, «El lado obscuro de la historia. Entrevista,»

47 El célebre economista e historiador que llegó a ser presidente de Italia y que fue el padre del editor de Ginzburg.

48 Carlo Ginzburg, «Historia y microhistoria. Carlo Ginzburg entrevistado por Mauro Boarelli,» Pasajes, no 44 (2014): 92. 
captar cosas, configuraciones, que la mirada tradicional deja de lado ${ }^{49}$.

En el ejemplo de Ojazos vemos una recopilación de investigaciones, de las cuales tres son inéditas, escritas entre 1991 y 1996: artículos que tratan objetos tan dispares como los mitos, los símbolos, las imágenes, la iconografía cristiana; o artículos que abordan conceptos tales como los de extrañamiento o estilo. Cada uno de esos artículos -que a su vez son ensayos breves- es un trozo de sí mismo: jirones que el autor se ha arrancado tiempo atrás y que pone en relación a partir de determinadas preocupaciones.

Es probable, como decíamos, que con este procedimiento el lector pueda desorientarse, pues el autor le exige un esfuerzo que otras obras lineales o convencionales le ahorran. En el fondo, lo que Ginzburg propone así es una suerte de contrapartida de la microhistoria, una forma narrativa apropiada: si con la reducción de la escala advertimos que no hay objetos históricos naturales u obvios, con el ensayo muestra que no hay tampoco una forma predeterminada o fatal de escribir historia. Un ensayo en el que predomina la estupefacción: "comprender menos, ser ingenuo, quedarse estupefactos, son reacciones que pueden llevarnos a ver más, a alcanzar algo más profundo, más cercano a la naturaleza» ${ }^{50}$.

Así, se escoge un determinado procedimiento narrativo, con ritmo cortante y cambio de puntos de vista, que actúa como un campo magnético particular, suscitando preguntas concretas y buscando documentos potenciales:

[...]en este sentido, un procedimiento como el discurso directo libre [estilo directo libre], nacido para responder en el campo de la ficción, a una serie de preguntas planteadas por la historia, puede ser considerado un desafío indirecto

49 «Introducción» a Ninguna isla es una isla, 12.

50 Carlo Ginzburg, Ojazos de madera. Nueve reflexiones sobre la distancia (Barcelona: Península, 2000), 27. 
lanzado a los historiadores. Un día ellos podrían hacerlo propio, en formas que hoy no logramos imaginar ${ }^{51}$.

Justamente por eso, quizá al lector aún le queden dudas sobre la coherencia del volumen; quizá aún le pueda parecer de difícil acomodo que temas tan diferentes permitan ser encajados dentro de ese hilo conductor. No obstante, esta forma de operar no es nueva en Carlo Ginzburg. Recordemos, por un lado, que algo semejante ocurría con su libro Miti, emblemi, spie, en donde, pese a tratarse de piezas sueltas, el autor nos alertaba muy sucintamente sobre su congruencia: la de la morfología en la historia.

Tal y como la entendía entonces, y como reaparece en Ojazos, la morfología se refiere a los parentescos de familia -al modo de Ludwig Wittgenstein o de Vladimir Propp-que el observador percibe entre formas culturales distantes o diferentes. Por consiguiente, objetos diversos pueden tener una coherencia secreta y se puede descubrir una conexión entre fuentes históricas alejadas unas de otras.

Por eso, tanto en este como en sus otros volúmenes, los derroteros que emprende son milenarios y, como él mismo nos advierte, «el camino que voy a seguir (será) aceptablemente tortuoso». Se trata de un camino que puede llevar, por ejemplo, desde Cicerón hasta Feyerabend o desde el emperador Marco Aurelio al crítico ruso Víctor Sklovski, «un camino fatigoso que requerirá cantidad de idas y venidas espaciales y temporales» ${ }^{52}$. Un vaivén, pues.

Además, Ginzburg despliega una extraordinaria erudición, con copiosas, torrenciales referencias que parecen brotar simultáneamente y en competencia para hacerse un hueco en el relato; lo que deslumbra es ese continuo y desordenado vaivén que hace obligatoria la tutela del lector

51 Carlo Ginzburg, «La áspera verdad. Un desafío de Stendhal a los historiadores,» en El hilo y las huellas, Lo verdadero, lo falso, lo ficticio (Buenos Aires: FCE, 2010), 266.

52 Ginzburg, Ojazos de madera, 18, 88. 
admirado y fatigado, un lector que precisa la guía y la mano firme de un autor que sabe dónde lo quiere llevar.

Ésta, que es la mejor virtud de Ginzburg, es también el motivo principal de los reproches frecuentes que se le dirigen. En efecto, cuando el lector se aventura en un ensayo de Ginzburg -desde Occhiacci hasta Nondimanco- no sabe cuál es el objeto auténtico de la obra, porque, pese a su enunciado explícito -la distancia cultural, la literatura, la prueba o la verdad-, detrás siempre hay un su texto, una meta implícita, un objeto escondido que justifica.

Un motivo que justifica ese itinerario tortuoso que el autor ha emprendido y jalonado a partir de los atisbos que va hallando y que a modo de señales le permiten ir avanzando. Y así, por ejemplo, Feyerabend, el célebre filósofo de la ciencia que se autoproclamara anarquista y contrario a las verdades instituidas autoritariamente por el saber institucional, aparece en el capítulo dedicado al estilo estético. ¿Con qué fines? ¿Por sus declaraciones a propósito de la inconmensurabilidad de las obras? En realidad, Feyerabend es evocado, analizado $\mathrm{y}$ finalmente denunciado por sus lamentables y tibias afirmaciones, por sus olvidos y por no asumir en la vejez, en la autobiografía que escribiera poco antes de morir, la responsabilidad como oficial del ejército del Tercer Reich.

¿Cuál sería el objeto escondido de esa alusión de Ginzburg? No lo es Feyerabend, como tampoco lo es Proust, ni Dostoievski ni cualquier otro propiamente hablando, ni tampoco el concepto de estilo, es decir, lo explícito del ensayo, sino el paradigma relativista o el escepticismo epistemológico. El extrañamiento, nos dice en Ojazos..., es un antídoto contra el riesgo más habitual, el de «dar por descontada la realidad», lo cual tiene unas «implicaciones antipositivistas» obvias. Ahora bien, eso se señala para enfatizar la oposición « con la mayor claridad posible a las teorías de moda que tienden a difuminar, hasta hacerlas indistinguibles, las fronteras entre historia y ficción ${ }^{53}$. Algo que, como él ha destacado en otras

53 Ginzburg, Ojazos de madera, 18, 39. 
ocasiones, nos deja desprotegidos, por ejemplo, frente a la negación del Holocausto y de la verdad histórica.

En efecto, junto con la escritura fragmentaria, el segundo aspecto recurrente es precisamente este, su rechazo a quienes difuminan los límites entre los relatos de ficción y las narraciones históricas, una preocupación que abandera los textos incluidos en Il filo e le tracce y que, en general, le ha preocupado especialmente en los últimos años:

Hoy en día términos como verdad o realidad se volvieron, para algunas personas, impronunciables a menos que estén encerrados entre comillas, escritas o mimadas. Este gesto ritual, difundido en los ámbitos académicos estadounidenses, antes de volverse una moda espontánea e involuntaria [irriflessa] fingía exorcizar el espectro del positivismo ingenuo: la actitud de quien considera posible conocer de manera directa, sin mediaciones, la realidad. Por detrás de esta polémica previsible solía asomar una posición escéptica, diversamente argumentada ${ }^{54}$.

De nuevo, como en anteriores ocasiones, trata de explorar la relación existente entre verdad histórica, ficción y falsedad a través de una serie de casos, de auténticas miniaturas en muchos capítulos: los protocolos de Sión, la conversión de unos hebreos en Mallorca, Stendhal, unos caníbales brasileños, la Inquisición, etcétera. Es la misma crítica que podemos hallar en Ojazos de madera o Rapporti di forza y ello porque, en los últimos tiempos, Ginzburg ha querido significarse como un antirrelativista: como alguien que, frente a Nietzsche, aún cree en la verdad (en mayúsculas), siendo al tiempo consciente de que han pasado los tiempos del positivismo ingenuo.

Así que se enfrenta con coraje a los textos, a las fuentes, y a las múltiples maneras de leerlos. ¿Porque... qué es una fuente? ¿Cuándo decimos que contiene la verdad? Si resulta falsa, ¿la descartamos? Según señala Ginzburg, «nadie pensará que sea inútil estudiar las leyendas falsas, los falsos acontecimientos, los documentos falsos: pero una toma de

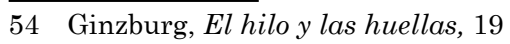


posición preliminar sobre su falsedad y autenticidad es, como mínimo, indispensable» ${ }^{55}$.

Esta es la dualidad metodológica que Ginzburg considera necesaria. Enfrentémonos abiertamente, pues, a cualquier fuente, observemos la existencia de múltiples voces, mostremos incluso la pugna por representar la realidad. De ese modo, escarbando en los textos, incluso contra la intención de quienes los produjeron, uno puede hacer que salgan voces incontroladas: como las de aquellos hombres y mujeres que se sustraían de los estereotipos judiciales en los procesos de brujería, como Menocchio.

Es decir, realidad, imaginación y falsificación se entrecruzan a menudo, unas veces en contraposición, otras alimentándose mutuamente. En fin, el hilo es lo que deseamos decir y demostrar, la huellas nos remiten a algo opaco, a posibilidades, a esos elementos incontrolados, a silencios incluso, que todo texto ofrece y que el historiador ha de tener en cuenta. En todo caso, como concluye Ginzburg,

\begin{abstract}
Los historiadores -escribió Aristóteles en Poética, 51bhablan de aquello que ha sido (lo verdadero); los poetas, de aquello que podría haber sido (lo posible). Pero desde luego, lo verdadero es un punto de llegada, no un punto de partida. Los historiadores (y, de un modo distinto, los poetas) hacen por oficio algo propio de la vida de todos: desenredar el entramado de lo verdadero, lo falso y lo ficticio que es la urdimbre de nuestro estar en el mundo ${ }^{56}$.
\end{abstract}

En ese sentido, Ginzburg insiste especialmente en sus últimas obras en un corolario de su lucha contra el relativismo. Así, señala que las posibilidades del texto o de la vida no deben hacernos olvidar la importancia de la prueba, pues es la que permite que la verdad sea el punto de llegada, la que pone la barrera frente al escepticismo, la que marca distancias entre la narrativa de ficción y la histórica, la que hace que la historia

55 Ginzburg, El hilo y las huellas, 19.

56 Ginzburg, El hilo y las huellas..., 17-18. 
sea una ficción probada ${ }^{57}$, la que evita a la postre que el propio Ginzburg sea clasificado junto con sus enemigos.

La prueba ha adquirido para él tal relevancia en los últimos tiempos que llega incluso a sorprenderse de que el término esté ausente de sus obras iniciales y que, en cambio, sea la palabra indicio la que domine ${ }^{58}$. En un texto reciente, titulado "Reflexiones sobre una hipótesis» y en el que hacía un balance de su mencionado "paradigma indiciario», Carlo Ginzburg señalaba:

[...]me impresiona mucho el hecho de que no ha existido la menor discusión en torno de la cuestión de la prueba en el ensayo de 1979 --es decir, sobre los procedimientos formulados históricamente, y negociables históricamente, que permiten distinguir una conjetura verdadera de una conjetura falsa. Y digo muy bien falsa, y no ficticia o inventada.

(...)

Es posiblemente esta experiencia de investigación, impuesta por las circunstancias, la que me condujo a descubrir la existencia de una antigua retórica fundada sobre las pruebas, en contra de la retórica moderna y postmoderna opuesta a esas mismas pruebas: para decirlo más brevemente, Aristóteles en contra de Nietzsche y de sus epígonos. Los ensayos compilados bajo el título Rapporti di forza parten de esta oposición para proponer, a través de una serie de ejemplos, la posibilidad de leer una serie de indicios como si fuesen otras tantas pruebas (por ejemplo, el famoso espacio en blanco del libro La educación sentimental) ${ }^{59}$.

No obstante, no olvidemos dos cosas: que la historia se construye; que no nos sirve una noción de prueba ingenuamente positivista. Lo que necesitamos, como señala reiteradamente, es renegociar las reglas una vez más, obteniendo un concepto

57 «Carlo Ginzburg: Je préfère faire confiance au réel, entrevista por Florence Noiville», Le Monde, París, 19 de enero de 2006, acceso el 20 de diciembre de 2019, https://www.lemonde.fr/livres/article/2006/01/19/carlo-ginzburg-je-prefere-faireconfiance-au-reel_732268_3260.html.

58 «Carlo Ginzburg. "Quien piensa que la realidad es solo lo que se toca no entiende nada”, entrevista por Claudio Martyniuk,» Debates Republicanos, acceso el 20 de diciembre de 2019, http://unioncivicaradical.blogspot.com/2007/09/ginzburg-quienpiensa-que-la-realidad.html.

59 Ginzburg, «Reflexiones sobre una hipótesis: el paradigma indiciario, veinticinco años después», 9-11. 
más sutil de prueba histórica. ¿Por qué? Porque uno no puede olvidar la historicidad de los instrumentos historiográficos. Por ello, algo ha de cambiar si hemos de investigar asuntos que no son los tradicionales de la disciplina. La noción de prueba que se utilizaba para la historia política o militar del siglo XIX no es, pues, la que podemos aplicar a la historia social y cultural de nuestros días, o a la microhistoria ${ }^{60}$.

Pues bien, si volvemos de nuevo a Ojazos de madera hallaremos algo semejante, aunque planteado de modo diferente, porque lo importante ahora no es (solo) el relativismo o el escepticismo, sino (también) la distancia. Y este es, diríamos, el tercero de los aspectos fundamentales que podemos ver en las obras más recientes de Carlo Ginzburg: el problema de la distancia, el de la dificultad y la necesidad del extrañamiento, el de la dificultad de la observación.

No se puede afirmar que esa preocupación sea nueva. Ya en 1980 señalaba las semejanzas existentes entre la mirada microhistórica y la que implica el extrañamiento, pues en ambos casos se cambia el punto de vista para así obtenerse conexiones y significados diferentes de los habituales, consagrados y trillados ${ }^{61}$.

De todos modos, en el caso de Ojazos el planteamiento es mucho más explícito: en cada uno de nosotros hay un forastero que se siente incómodo dentro de su propia identidad, un Pinocho que nos mira sin entender o un Pinocho al que miramos sin adivinar sus intenciones o su zozobra. Si el otro está dentro de nosotros (con resonancias polifónicas), al extraño, al diferente y al distante habrá que entenderlos como traslados o proyecciones de esa parte interna u oscura de uno mismo.

En Ginzburg, que ha leído con fruición y con aprovechamiento a Mijail Bajtín, no ha de extrañarnos semejante posición; en un historiador que ha frecuentado a

60 Ginzburg, «El lado obscuro de la historia. Entrevista,»

61 Ginzburg. Tentativas..., 175. 
Sigmund Freud como referente e inspirador de su perspectiva, no ha de sorprendernos que acepte como propia la tesis de la «inquietante extranjeridad» que anida en nuestro interior: lo siniestro.

Extranjeridad, extrañamiento, distancia, polifonía, elementos todos que provienen de sus primeros trabajos, que estuvieron siempre ahí y que han ido desvelándose, tomando forma:

Creo que puedo decir que, en mi caso, la conciencia de esta proximidad se ha fortalecido a través de una larga familiaridad con los procesos de la Inquisición: documentos en los que la alternancia de las voces de los jueces y de los imputados a menudo oculta un abuso de los primeros sobre los segundos, acompañado de una violencia que siempre es cultural, y a veces física. Para poder captar este entrelazamiento de voces sin deformarlo, el historiador debe aprender a esterilizar los instrumentos de análisis: en otras palabras, debe aprender a no proyectar sus propias expectativas y sus propios prejuicios sobre los documentos. Tiene que aprender a dejar de lado lo que sabe, a mirar la realidad como algo opaco, incomprensible, extraño; debe renunciar a entender para entender más ${ }^{62}$.

\section{Bibliografia}

Canfora, Luciano y otros. "Paradigma indiziario e conoscenza storica. Dibattito su 'Spie' di Carlo Ginzburg.» Quaderni di Storia, no 11 (1980): 3-18, no 12 (1980): 3-54, y no 14 (1981): 159-187.

Barthes, Roland. Ensayos críticos. Buenos Aires: Seix Barral, 2003, [1967].

Boyd, Kelly, ed. Encyclopedia of Historians and Historical Writing. Londres: Fitzroy Dearborn, 1999.

Burns, Robert M., ed. Historiography (Critical Concepts in Historical Studies. Londres: Routledge, 2005.

62 Carlo Ginzburg, «Lectores de Proust. ¿Qué pueden aprender los historiadores de una narración tan sui generis como la Recherche?,» Pasajes: Revista de pensamiento contemporáneo, $\mathrm{n}^{\circ} 45$ (2014): 95. 
Chakrabarty, Dipesh. «La traducción de los mundos de la vida al trabajo y a la historia.» En Al margen de Europa. Barcelona: Tusquets, 2008.

Gargani , Aldo, ed. Crisi della Ragione. Turín: Einaudi, 1979.

Ginzburg, Carlo. Los benandanti. Brujería y cultos agrarios entre los siglos XVI y XVII. Guadalajara: Universidad de Guadalajara, 2005. [ed. original 1966].

El queso y los gusanos. Barcelona: Muchnik, 1981. [ed. original de 1976].

. Mitos, emblemas, indicios (Barcelona, Gedisa, 1989. [ed. original de 1986].

. Historia nocturna. Barcelona, Muchnik eds., 1991. [ed. original de 1989].

. "Microhistoria: dos o tres cosas que sé de ella.» Manuscrits, $\mathrm{n}^{\circ} 12$ (1994): 13-42.

- Ojazos de madera. Nueve reflexiones sobre la distancia. Barcelona: Península, 200. [ed. original de 1998].

Rapporti di forza: Storia, retorica, prova. Milán: Feltrinelli, 2000.

. «De près, de loin. Des rapports de force en histoire. Entretien avec Carlo Ginzburg.» (realizada por Philippe Mangeot) Vacarme, ${ }^{\circ} 18$ (2002): 4-12.

. Ninguna isla es una isla. Villahermosa: Universidad Juárez Autónoma de Tabasco, 2003. [ed. original de 2002].

"Intervención sobre el paradigma indiciario.» En Tentativas. Morelia: Universidad Michoacana, 2003. . "Carlo Ginzburg: L'historien et l'avocat du diable. Entretien avec Charles Illouz et Laurent Vidal.» Genèses, n ${ }^{\circ}$ 53 (2003):113-138 y n 54 (2004): 112-129. 
«På historiens nattside. Carlo Ginzburg i samtale med Trygve Riiser Gundersen.» Samtiden, nº 2 (2003).

«Reflexiones sobre una hipótesis: el paradigma indiciario, veinticinco años después.» Contrahistorias, $\mathrm{n}^{0} 7$ (2006-2007): 9-11.

«Señales. Raíces de un paradigma indiciario.» En Aldo Gargani, comp., Crisis de la razón. Nuevos modelos en la relación entre saber y actividades humanas, 55-99. México: Siglo XXI,1983.

. «Latituds, esclaus i la Bíblia. Un experiment de microhistoria.» Afers, $\mathrm{n}^{\circ} 57$ (2007): 355-373.

. El hilo y las huellas. Lo verdadero, lo falso, lo ficticio. Buenos Aires: FCE, 2010. [ed. original de 2006].

"La áspera verdad. Un desafío de Stendhal a los historiadores.» En El hilo y las huellas. Lo verdadero, lo falso, lo ficticio. Buenos Aires: FCE, 2010.

. «Maquiavelo, la excepción y la regla. Líneas de una investigación en curso.» Ingenium, $\mathrm{n}^{\circ} 4$ (2010): 5-28.

. The Cheese and the Worms. Baltimore: John Hopkins University Press, 2013.

. «Lectores de Proust. ¿Qué pueden aprender los historiadores de una narración tan sui generis como la Recherche?.» Pasajes: Revista de pensamiento contemporáneo, $\mathrm{n}^{\circ} 45$ (2014): 91-99.

«Entretien: Carlo Ginzburg dialogue avec Éric Dayre.» En Imagination et histoire: enjeux contemporains, dirigido por Marie Panter, Pascale Mounier, Monica Martinat y Matthieu Devigne, 111-124. Rennes: Presses Universitaires de Rennes, 2014. Edición en digital. https://books.openedition. org/pur/49600.

2018.

. Nondimanco Machiavelli, Pascal. Milán: Adelphi, 
«Los benandanti, cincuenta años después.» Taller de letras, $n^{\circ} 62$ (2018): 91-101.

Les batailles nocturnes. París: Flammarion, 2019.

. Il formaggio e i vermi. Milán: Adelphi, 2019.

. «La Storia o è eretica o non è Storia, Eentrevista por Simonetta Fiori». La Repubblica, Roma, 11 de septiembre de 2019. Acceso el 20 de diciembre de 2019. https://rep.repubblica. it/pwa/intervista/2019/09/11/news/carlo_ginzburg_la_ storia_o_e_eretica_o_non_e_storia_-235698431/.

. Süss, Amaranta. «El lado obscuro de la historia. Entrevista-versión en español», sinpermiso, 12 de marzo de 2006. Acceso el 20 de diciembre de 2019. http://www.sinpermiso. info/textos/el-lado-obscuro-de-la-historia-entrevista.

«Ginzburg Carlo: Je préfère faire confiance au réel. Entrevista por Florence Noiville». Le Monde, París, 19 de enero de 2006. Acceso el 20 de diciembre de 2019. https:// www.lemonde.fr/livres/article/2006/01/19/carlo-ginzburg-jeprefere-faire-confiance-au-reel_732268_3260.html.

. «La notion de vérité fait partie de nous. Entretien avec Carlo Ginzburg». Entrevista por Ivan Jablonka, La Vie des idées, 23 de octubre de 2015, acceso el 20 de diciembre de 2019, http://www.laviedesidees.fr/La-notion-de-verite-faitpartie-de-nous.html

. «Interview with 2015 Tanner Lecturer Carlo Ginzburg». Entrevista por Matthew Collins, 6 de marzo de 2015. Acceso el 20 de diciembre de 2019. http:// mahindrahumanities.fas.harvard.edu/news/interview-2015tanner-lecturer-carlo-ginzburg-matthew-collins.

. «Historia y microhistoria. Carlo Ginzburg entrevistado por Mauro Boarelli.» Pasajes, nº 44 (2014): 92. . "Carlo Ginzburg. "Quien piensa que la realidad es sólo lo que se toca no entiende nada", entrevista por Claudio Martyniuk.» Debates Republicanos. Acceso el 20 de diciembre 
de 2019. http://unioncivicaradical.blogspot.com/2007/09/ ginzburg-quien-piensa-que-la-realidad.html.

Grafton, Anthony. «History's postmodern fates.» Daedalus Vol. 135, $\mathrm{n}^{\circ} 2$ (2006): 54-69.

Grendi, Edoardo. «¿Repensar la microhistoria?.» Entrepasados. Revista de Historia, $\mathrm{n}^{\circ} 10$ (1996): 131-140.

Levi, Giovanni. «O trabalho do historiador: pesquisar, resumir, comunicar.» Revista Tempo, no 20 (2014): 3-4.

Serious Science. «Microhistory. Historian Carlo Ginzburg on the value of an individual, geopolitical traditions in history and globalization.» 25 de junio de 2015 . Acceso el 20 de diciembre de 2019. http://serious-science.org/microhistory-2893 y https:// www.youtube.com/watch?v=VFh1DdXToyE.

Serna, Justo y Anaclet Pons. microHistoria. Las narraciones de Carlo Ginzburg. Granada: Comares, 2019.

Thouard, Denis, ed. L’interprétation des indices - Enquête sur le paradigme indiciaire avec Carlo Ginzburg. Lille: Presses Universitaires du Septentrion, 2007. DOI: https://doi. org/10.4000/books.septentrion.65335.

\section{Citar este artículo}

Serna, Justo, y Anaclet Pons. "Carlo Ginzburg. Cuando el historiador amoneda un símbolo.» Historia $Y$ MEMORIA, $\mathrm{n}^{\circ}$ Especial (2020): 307-345. DOI: https:/doi. org/10.19053/20275137.nespecial.2020.11591. 